\title{
O Papel da Amplitude Visuoatencional e da Consciência Fonêmica na Aprendizagem da Leitura
}

\section{The Role of Visual Attention Span and Phonemic Awareness in Learning to Read}

\author{
Renan de Almeida Sargiani ${ }^{*}, a$, Maria Regina Maluf ${ }^{a, b}$ \& Marie-Line Bosse ${ }^{c}$ \\ ${ }^{a}$ Universidade de São Paulo, São Paulo, SP, Brasil, \\ ${ }^{b}$ Pontifícia Universidade Católica de São Paulo, São Paulo, SP, Brasil \\ $\&^{c}$ Université de Grenoble-Alpes, Grenoble, França
}

\begin{abstract}
Resumo
Este estudo objetivou verificar as relações entre amplitude visuoatencional (AVA), consciência fonêmica (CF) e desempenho em leitura em uma amostra de 48 alunos de $1^{\circ}, 3^{\circ}$ e $5^{\circ}$ anos do ensino fundamental de uma escola pública de São Paulo. As crianças foram avaliadas em três sessões em tarefas de leitura de palavras isoladas, AVA, CF, inteligência não verbal, memória fonológica e limiar de identificação de letras. Os resultados indicam que a AVA e a CF se relacionam com a leitura desde $o 1^{\circ}$ até o $5^{\circ}$ ano e que essas relações são mais fortes no $1^{\circ}$ ano, mas continuam tendo um papel relevante no $3^{\circ}$ ano e no $5^{\circ}$ ano, principalmente na leitura de pseudopalavras e palavras irregulares. Palavras-chave: Amplitude visuoatencional, consciência fonêmica, desempenho em leitura.
\end{abstract}

\begin{abstract}
This study aimed to verify the relationship between visual attention span (VAS), phonemic awareness (PA) and reading performance in a sample of 48 students from the $1^{\text {st }}, 3^{\text {rd }}$ and $5^{\text {th }}$ grade from a public elementary school in Sao Paulo. Children were assessed in three sessions through a battery of tasks, which included single word reading, VAS, PA, nonverbal intelligence, phonological memory and letter identification threshold. Results showed that the VAS and PA correlated with performance in reading from $1^{\text {st }}$ to $5^{\text {th }}$ grade, and they play a more important role at $1^{\text {st }}$ grade, but remain relevant in $3^{\text {rd }}$ and $5^{\text {th }}$ grade, especially in the reading of nonwords and irregular words.

Keywords: Visual attention span, phonemic awareness, reading performance.
\end{abstract}

A habilidade de leitura de palavras em sistemas alfabéticos de escrita, como é o caso do português, exige estabelecer relações entre os sons (fonemas) das palavras faladas e seus símbolos gráficos (letras, grafemas) correspondentes. Por esta razão, a habilidade de leitura depende tanto de componentes do processamento fonológico (e.g. consciência fonêmica, nomeação seriada rápida) como de componentes do processamento visuoatencional (e.g. amplitude visuoatencional; Ans, Carbonnel, \& Valdois, 1998; Bosse \& Valdois, 2009; Sargiani, 2013). No presente estudo, objetivou-se verificar as contribuições específicas

*Endereço para correspondência: Rua Itamogi, 120, Pirituba, SP, Brasil 05170-060. E-mail: sargiani@gmail.com Agradecemos ao Prof. Dr. Elizeu Coutinho de Macedo (Universidade Presbiteriana Mackenzie) por ter gentilmente fornecido o software Cronofonos utilizado nesta pesquisa. Agradecemos ao Conselho Nacional de Desenvolvimento Científico e Tecnológico (CNPq) pela bolsa de Mestrado concedida ao primeiro autor (número do processo 144973/2011-1) que possibilitou a execução desta pesquisa. Agradecemos também à Fundação de Amparo à Pesquisa do Estado de São Paulo (FAPESP) pela concessão, ao primeiro autor, da bolsa de Doutorado (número do processo 2013/12602-5) que possibilitou a escrita deste artigo. da consciência fonêmica e da amplitude visuoatencional para o desempenho em leitura de crianças brasileiras de diferentes séries do ensino fundamental.

Desde os anos 1970, na área da Psicologia Cognitiva da Leitura, tem-se demonstrado que a consciência fonológica (i.e, a habilidade de identificar, isolar ou manipular os sons da fala), é uma habilidade de processamento fonológico fundamental para a aprendizagem de leitura e de escrita (Adams, 1999; Maluf, 2005; Maluf, Zanella, \& Pagnez, 2006; Morais, Leite, \& Kolinsky, 2013; Santos \& Maluf, 2010). Dentre as sub-habilidades da consciência fonológica destaca-se o papel da consciência fonêmica (i.e., o conhecimento e o controle intencional sobre os menores sons da fala que são os fonemas; Yopp \& Yopp, 2000). No Brasil predominam os estudos sobre a consciência fonológica de modo geral, sem muitas especificações do papel específico da consciência fonêmica (Maluf et al., 2006).

A consciência fonêmica é importante, pois, auxilia na decodificação que é o processo principal pelo qual os leitores iniciantes leem palavras novas, palavras não-familiares ou pseudopalavras (Ehri, 2013a; Morais et al., 2013). Existem evidências da importância da consciência fonêmica na aprendizagem da linguagem escrita em dife- 
rentes ortografias alfabéticas, como o português, o francês, o inglês e o espanhol (Adams, 1999; Maluf \& Sargiani, 2013; Plaza \& Cohen, 2007; Santos \& Maluf, 2010; Sargiani, 2013; Share, 2004; Spinillo, Mota, \& Correa, 2010). A consciência fonêmica é considerada como fundamental para o estabelecimento do conhecimento sobre o sistema de leitura em diferentes modelos de aprendizagem de leitura (e.g. Ans et al., 1998; Bradley \& Bryant, 1983; Ehri, 2013a, 2013b; Harm \& Seidenberg, 1999; Ziegler \& Goswami, 2005).

Estudos mais recentes têm discutido os limites do papel da consciência fonêmica na aprendizagem da leitura, demonstrando, por exemplo, que crianças com dislexia do desenvolvimento podem apresentar dificuldades de leitura a despeito de bons níveis de consciência fonêmica (Bosse, Tainturier, \& Valdois, 2007; Castles \& Coltheart, 2004; Lobier, Zoubrinetzky, \& Valdois, 2012; Plaza \& Cohen, 2007). Além disso, alguns estudos apontam também para a importância de outras habilidades e processos cognitivos envolvidos na aprendizagem e desempenho em leitura, como a consciência morfológica (Deacon \& Kirby, 2004; Spinillo et al., 2010), nomeação seriada rápida (Corrêa \& Cardoso-Martins, 2012) e amplitude visuoatencional (Bosse \& Valdois, 2009; Sargiani, 2013).

Bosse et al. (2007) introduziram o conceito de amplitude visuoatencional (AVA) para explicar as dificuldades no processamento visual de conjuntos de letras em crianças disléxicas. A AVA (Visual Attention Span em inglês e Empan visuo-attentionnel em francês) foi definida como o número de elementos visuais distintos (e.g., números, letras) que podem ser processados simultaneamente com uma única fixação de olhar dentro de um conjunto multi-elementos (e.g. palavras, sequências numéricas). Hipotetiza-se que uma melhor capacidade de AVA beneficiaria a leitura e o armazenamento de regras ortográficas (Bosse, Chaves, Largy, \& Valdois, 2013; Valdois, 2008, 2010).

O conceito de AVA está fundamentado no modelo conexionista de memória multi-traço (MMT) de leitura de palavras polissilábicas proposto por Ans et al. (1998). Nesse modelo considera-se que a habilidade de leitura depende tanto de bons níveis de consciência fonêmica quanto de bons níveis de processamento visuoatencional. Quando as pessoas veem uma palavra escrita, existe um limite de letras que podem ser processadas simultaneamente, e esse espaço é chamado de janela visuoatencional. A amplitude visuoatencional é, portanto, o tamanho dessa janela, o qual possibilita o processamento individual das letras dentro do conjunto (palavra).

Buscando verificar as contribuições independentes da consciência fonêmica e da amplitude visuoatencional, Bosse e Valdois (2009) realizaram um estudo com crianças francesas consideradas como tendo um desenvolvimento típico. Este estudo, de cunho transversal, foi feito com crianças do $1^{\circ}$ ano, $3^{\circ}$ ano e $5^{\circ}$ ano de escolarização. Demonstrou-se que independentemente do processamento fonêmico, a AVA contribuiu para o desempenho em leitura em todos os anos escolares, mas que sua importância foi maior no $1^{\circ}$ ano, quando as crianças dependem mais da decodificação para ler e, portanto, dependem mais da consciência fonêmica e da AVA.

Muitos estudos têm sido feitos pela equipe de Sylviane Valdois na França, com crianças de desenvolvimento típico ou disléxicas de diferentes idades. Esses estudos têm mostrado que a amplitude visuoatencional não é um componente do processamento fonológico e contribui independentemente deste para a aprendizagem e o desempenho em leitura (Bosse et al., 2013; Bosse et al., 2007; Bosse \& Valdois, 2009; Dubois, De Micheaux, Noel, \& Valdois, 2007; Lobier et al., 2012; Valdois, 2008, 2010). No entanto, o papel dos processos visuoatencionais, especialmente o da amplitude visuoatencional, ainda tem sido pouco estudado internacionalmente, restringindo-se aos estudos com crianças francesas e inglesas (Lobier et al., 2012).

No presente estudo, buscou-se investigar as contribuições da AVA e da consciência fonêmica para a leitura de palavras, em crianças falantes do português do Brasil. Objetivou-se também verificar se a AVA e a consciência fonêmica melhoram com o aumento nos anos de escolarização. A relevância desses objetivos reside no fato de que embora numerosos estudos investiguem a importância da consciência fonêmica, eles são realizados, em sua maioria, com falantes do inglês (Ziegler \& Goswami, 2005) e são escassos os estudos sobre o papel da consciência fonêmica em português do Brasil (Maluf et al., 2006). Além disso, a recente produção de estudos sobre a AVA tem gerado dados muito relevantes, mas não foram encontradas, na revisão do presente estudo, pesquisas sobre o papel da AVA em falantes do português. Nesse sentido, este parece ser o primeiro estudo feito sobre o tema com crianças falantes do português do Brasil.

\section{Método}

O presente estudo foi realizado com delineamento correlacional e corte transversal e aprovado pelo Comitê de Ética da Pontifícia Universidade Católica de São Paulo (PUC-SP) sob o número CAAE 03085512.2.0000.5482. Todos os participantes foram autorizados a participar da pesquisa por meio de um Termo de Consentimento Livre e Esclarecido (TCLE) assinado pelos responsáveis.

\section{Participantes}

A amostra consistiu em 48 crianças brasileiras de uma escola pública da cidade de São Paulo, sendo 16 alunos do $1^{\circ}$ ano ( 9 meninos e 7 meninas), 16 alunos do $3^{\circ}$ ano (5 meninos e 11 meninas) e 16 alunos do $5^{\circ}$ ano (10 meninos e 6 meninas) do ensino fundamental de diferentes turmas e turnos. Como se observa na Tabela 1, as médias de idade variaram de 78 meses a 119 meses. Adotou-se como critério de seleção que as crianças conhecessem todas as letras do alfabeto (mesmo que ainda não soubessem ler) e que tivessem visão normal ou corrigida pelo uso de óculos. A média de inteligência não verbal das crianças no teste de Raven foi de 82,72 e a ANOVA permitiu verificar que não existiam diferenças significativas entre os grupos estudados $F(2,45)=0,256, p=0,775$. 
Sargiani, R. A., Maluf, M. R. \& Bosse, M.-L. (2015). O Papel da Amplitude Visuoatencional e da Consciência Fonêmica na Aprendizagem da Leitura.

Tabela 1

Características dos Participantes por Ano Escolar

\begin{tabular}{lcccc}
\hline & $1^{\circ}$ Ano & $3^{\circ}$ Ano & $5^{\circ}$ Ano & Total \\
\hline & $N=16$ & $N=16$ & $N=16$ & $N=48$ \\
& Média $(D P)$ & Média $(D P)$ & Média $(D P)$ & Média $(D P)$ \\
Idade cronológica (meses) & $78(4$ meses $)$ & $103(4$ meses $)$ & $119(5$ meses $)$ & $100(18$ meses $)$ \\
Percentil de Inteligência Não Verbal (Raven) & $85,25(19,28)$ & $81,31(14,81)$ & $81,62(17,51)$ & $82,72(17,02)$ \\
\hline
\end{tabular}

\section{Procedimentos e Instrumentos de Avaliação}

Os participantes foram avaliados em tarefas de leitura de palavras, consciência fonêmica e amplitude visuoatencional (AVA). A memória fonológica e a inteligência não verbal foram avaliadas como variáveis de controle por influenciarem no desempenho em leitura (Alloway, Gathercole, Willis, \& Adams, 2004; Gayan \& Olson, 2003). Além disso, uma tarefa de limiar de identificação de letras foi aplicada para controlar a taxa de processamento de letras individuais que pode influenciar nas medidas de AVA (Bosse et al., 2007; Bosse \& Valdois, 2009).

Todos os participantes foram avaliados em três sessões de aproximadamente 25 minutos cada. Na primeira sessão individual foram aplicadas as tarefas de leitura de palavras isoladas, AVA, limiar de identificação de letras e memória fonológica. Na segunda sessão individual, foram aplicadas as tarefas de consciência fonêmica. Na terceira sessão foi aplicado o teste Matrizes Progressivas Coloridas de Raven - escala especial (Angelini, Alves, Custódio, Duarte, \& Duarte, 1999), sob a forma coletiva (grupos de 8 alunos) para os alunos do $3^{\circ} \mathrm{e} 5^{\circ}$ anos e individual para os alunos do $1^{\circ}$ ano, de acordo com as normas de padronização do teste.

Tarefas de Leitura de Palavras Isoladas. Os participantes foram solicitados a ler em voz alta palavras exibidas isoladamente em um programa de computador. As palavras foram exibidas em um netbook de 10 polegadas usando o software CronoFonos (Capovilla, Capovilla, \& Macedo, 1998). As palavras foram escolhidas com base em tarefas de leitura de palavras de outros estudos (Pinheiro, 2006; Salles, 2005). Foram criadas 3 listas de palavras de alta frequência, sendo uma lista de palavras regulares, uma de palavras irregulares e outra de pseudopalavras. Cada lista continha 20 palavras organizadas pela extensão (possuíam entre 4 e 9 letras). Adicionalmente, foram feitas 3 listas com os mesmos critérios de quantidade, natureza, regularidade e extensão, mas com o diferencial de serem palavras de baixa frequência. Para os alunos do $1^{\circ}$ ano, que ainda estavam sendo iniciados na alfabetização, só foram aplicadas as palavras de alta frequência (60 palavras), enquanto os alunos do $3^{\circ}$ e $5^{\circ}$ ano leram as 120 palavras (listas de alta e baixa frequência). Exemplos: palavras regulares (duas - gostava); palavras irregulares (ouça - amanhã); pseudopalavras (posdava - puas). Antes do início da tarefa, as crianças faziam um treinamento com 3 palavras regulares, 3 palavras irregulares e 2 pseudopalavras. Atribuiu-se um ponto para cada palavra lida corretamente. Foram tomadas como escores as médias da porcentagem de acertos para cada lista de palavras: palavras regulares, palavras irregulares e pseudopalavras. No caso dos alunos do $3^{\circ}$ e $5^{\circ}$ ano, os desempenhos nas listas de palavras de alta e baixa frequência foram somados, fornecendo um único escore para cada tipo de palavra. Além disso, dividiu-se o tempo gasto para a leitura de todas as palavras (em segundos) pela quantidade de itens a serem lidos, e tomou-se a média desse valor como um escore de velocidade de leitura.

Tarefas de Avaliação da Amplitude Visuoatencional. Foram aplicadas duas tarefas que foram utilizadas na pesquisa de Bosse e Valdois (2009). Trata-se de uma tarefa de relato global (dividida em duas medidas, relato global de letras e relato global de conjuntos) e uma tarefa de relato parcial, que foram apresentadas utilizando um netbook de 10 polegadas com Windows 7 . As tarefas foram construídas utilizando o software de desenvolvimento E-prime pelo Laboratoire de Psychologie et NeuroCognition (LNPC) da Université de Grenoble II - Pierre Mendès-France (Grenoble - França).

Relato global. Foram apresentados 20 conjuntos de cinco letras (e.g. R H S D M) formados aleatoriamente a partir de 10 consoantes (B, P, T, F, L, M, D, S, R, H). Os conjuntos eram fixos, exibidos um por vez e seguindo uma mesma ordem. Durante o exame, foi solicitado que os participantes fixassem seu olhar em um ponto central que aparecia por $1000 \mathrm{~ms}$, seguido por uma tela preta por $50 \mathrm{~ms}$. Em seguida, era exibida a sequência de 5 letras horizontalmente centralizadas no ponto de fixação, por $200 \mathrm{~ms}$, e o pesquisador solicitava que os participantes nomeassem o maior número de letras que pudessem, imediatamente após elas desaparecerem, sem a necessidade de nomeá-las na ordem em que foram apresentadas. As letras foram exibidas 10 vezes, sendo que apareciam duas vezes em cada uma das cinco posições. As letras foram apresentadas em maiúsculas (caixa alta, fonte Arial, 7 milímetros de altura), em cor preta sobre fundo branco. Os conjuntos não tinham letras repetidas e duas letras subsequentes nunca correspondiam a um grafema em português (e.g. CH, LH). As 5 letras também não permitiam a formação de um esqueleto de palavras em português (e.g., "F L R S T" = FLoReSTa). A média de porcentagem de letras corretamente identificadas independentemente da ordem foi chamada de "relato global de letras". A média de porcentagem de conjuntos 
corretamente identificados foi chamada de "relato global de conjuntos".

Relato parcial. Foram apresentados 50 conjuntos de cinco letras (e.g. T H R F D) construídos com as mesmas 10 consoantes, critérios, tamanhos e fontes utilizados na tarefa de relato global. Cada letra aparecia 25 vezes, sendo 5 vezes em cada posição. Os conjuntos não tinham letras repetidas. Foi solicitado que o participante falasse unicamente o nome de uma letra-alvo que era indicada por uma barra vertical (5 milímetros de altura) apresentada por $50 \mathrm{~ms}$ após o conjunto de cinco letra ser exibido (como na tarefa anterior, por $200 \mathrm{~ms}$.). A barra era apresentada $1 \mathrm{~cm}$ abaixo da posição onde a letra alvo era exibida. Cada letra foi usada como alvo uma vez em cada posição. Denominou-se "relato parcial" a porcentagem de letras-alvo corretamente relatadas.

Tarefas de Consciência Fonêmica. A consciência fonêmica foi avaliada por meio de 4 tarefas distintas aplicadas na seguinte ordem: (a) deleção fonêmica, (b) acrônimos, (c) segmentação fonêmica e (d) trocadilhos. Os alunos do primeiro ano não fizeram a última tarefa (trocadilhos), pois essa é considerada mais difícil do que as demais (Bosse \& Valdois, 2009). Para a análise do desempenho em consciência fonêmica foi atribuído um ponto para cada resposta certa em cada uma das tarefas. $\mathrm{O}$ total de acertos foi convertido em porcentagem e depois foi calculada a média dos participantes por ano escolar em cada uma das tarefas.

Deleção fonêmica. Esta tarefa foi baseada na prova de subtração de fonema inicial de Guimarães (2005, p. 148) e na prova de deleção fonêmica utilizada por Bosse e Valdois (2009). A tarefa objetiva verificar a habilidade das crianças de extrair os fonemas iniciais das palavras. Apresenta-se uma série de palavras (uma por vez) e solicita-se que a criança repita cada palavra sem o fonema inicial. A subtração do fonema inicial faz com que o restante da palavra forme uma nova palavra real. Ex: a criança ouve "casa" e tem que responder "asa". No total foram aplicados 20 itens de avaliação e 2 de treino. Após 5 erros consecutivos a tarefa era interrompida.

Acrônimos. Esta tarefa foi baseada na prova de Acrônimos utilizada por Bosse e Valdois (2009). Os pares de palavras são formados sempre por uma palavra iniciada por um fonema consonantal e uma palavra iniciada por um fonema vocálico. Solicita-se que as crianças extraiam os fonemas iniciais de cada uma das duas palavras e que então formem uma sílaba a partir desses fonemas. Ex.: A criança ouve "bolo" e "anel" e deve responder "ba". A tarefa é composta por uma lista de 10 pares de palavras para a avaliação e 2 pares de palavras para treino. A tarefa era interrompida após 3 erros consecutivos.

Segmentação fonêmica. Esta tarefa foi baseada nas provas usadas por Guimarães $(2005$, p. 141) e Bosse e Valdois (2009). A tarefa é composta por 17 palavras, sendo 2 de treinamento e 15 de exame. Após a apresentação oral das palavras era solicitado que os participantes falassem em voz alta a palavra em seus menores sons possíveis. $\mathrm{O}$ conjunto de itens é formado por 4 monossílabas, 8 dissílabas e 2 polissílabas. A tarefa era interrompida após 5 erros consecutivos. Apenas eram consideradas certas as palavras segmentadas totalmente. Não foram considerados corretos os itens em que as crianças falavam os nomes das letras ao invés dos fonemas.

Trocadilhos. Esta atividade foi baseada na tarefa Spoonerism descrita por Bosse e Valdois (2009). Foram apresentadas oralmente 12 pares de palavras (2 pares de treino e 10 de exame) e foi solicitado à criança que ouvisse atentamente as palavras e trocasse os sons iniciais de cada dupla de palavras, formando duas novas pseudopalavras. Ex.: A criança ouve "banana" e "camelo" e responde "Canana" e "Bamelo". A tarefa era interrompida após 3 erros consecutivos.

Tarefas de Controle. Limiar de identificação de letras. Essa prova é a mesma utilizada por Bosse e Valdois (2009) e consiste na exibição das 10 consoantes (B, P, T, F, L, M, D, S, R, H). Essas consoantes são apresentadas em um total de 50 itens, exibidos em diferentes tempos de exibição (33, 50, 67, 84 e 101ms). A diferença (17ms) corresponde ao tempo de atualização do monitor. As letras tinham as mesmas características das utilizadas nas tarefas de AVA e foram apresentadas no centro da tela após a exibição de um ponto de fixação central por $1.000 \mathrm{~ms}$. Após a letra, foram exibidos alguns símbolos (chamados de máscara) que não estão associados a nenhum som específico (parecidos com flocos de neves), utilizados para controlar a duração exata da apresentação do estímulo e efetivamente interromper o processamento do estimulo anterior. A máscara tinha $13 \mathrm{~mm}$ de altura, $37 \mathrm{~mm}$ de largura e era exibida por $150 \mathrm{~ms}$. Os itens do teste foram precedidos por 10 itens de treino (dois para cada tempo de apresentação) e os participantes receberam feedback indicando se a resposta estava certa ou errada. Como existiam 5 tempos de apresentação das letras, cada tempo equivalia a um peso diferente, de modo que a menor duração tinha o maior peso por ser mais difícil de ser acertada (o peso atribuído foi de 5 pontos para $33 \mathrm{~ms}, 4$ pontos para $50 \mathrm{~ms}$, 3 pontos para $67 \mathrm{~ms}, 2$ pontos para $84 \mathrm{~ms}$ e 1 ponto para $101 \mathrm{~ms}$ ). Para calcular o limiar de identificação de letras, a soma de acertos por tempo de apresentação foi multiplicada pelos pesos e depois todos os pontos ponderados foram somados resultando no escore.

Memória fonológica (Dígitos). Utilizou-se o subteste de Dígitos do teste WISC-III (Figueiredo, 2002) como uma medida de memória fonológica (ou memória verbal de curto prazo). Esse subteste é dividido em uma série direta e uma série inversa e consiste em solicitar que os participantes repitam um conjunto de dígitos que o experimentador apresenta oralmente. Ao todo são 8 séries para ordem direta e 7 para ordem inversa. Cada série é composta por 2 itens, com o mesmo número de dígitos cada, a cada série o número de dígitos aumenta. Primeiramente é aplicada a ordem direta e em seguida a inversa. $\mathrm{O}$ teste é interrompido quando o participante não consegue acertar dois itens consecutivos. A pontuação máxima é de 30 pontos. 
Sargiani, R. A., Maluf, M. R. \& Bosse, M.-L. (2015). O Papel da Amplitude Visuoatencional e da Consciência Fonêmica na Aprendizagem da Leitura.

Inteligência não verbal (Raven). O teste Matrizes Progressivas Coloridas de Raven é composto por 36 itens divididos em 3 séries de 12 itens: A, Ab e B. Esses itens exigem diferentes raciocínios e estão dispostos em ordem de dificuldade crescente. Cada série inicia com itens mais fáceis que vão progressivamente aumentando de dificuldade. Os itens são desenhos (matrizes) em que uma das partes está faltando e o objetivo é encontrar dentre algumas opções qual a alternativa que preenche a matriz corretamente. $\mathrm{O}$ teste está padronizado para a população brasileira, tanto para a aplicação individual quanto coletiva (Angelini et al., 1999).

\section{Procedimentos de Análise}

Foram feitas análises individuais para cada um dos anos escolares $\left(1^{\circ}\right.$ ano, $3^{\circ}$ ano e $5^{\circ}$ ano) e análises para todos os anos escolares juntos (análise transversal). Primeiramente, foi feita uma análise descritiva dos resultados de cada um dos anos escolares, calculando as médias e desvios-padrão de todas as variáveis. Logo após, foi realizada a análise de variância (ANOVA) para verificar se existia variância nas médias obtidas pelos participantes por ano escolar em cada uma das variáveis avaliadas. Após a ANOVA foi realizado um teste post hoc de Bonferroni, para realizar comparações múltiplas das médias, assim possibilitando especificar quais as médias que se diferenciaram significativamente. Em seguida, calculou-se a correlação parcial entre cada uma das variáveis avaliadas descontando o efeito da variável idade. Logo após, foi calculada novamente a correlação parcial entre cada uma das variáveis, mas desta vez descontando o efeito de todas as variáveis de controle: idade, memória fonológica, limiar de identificação de letras e inteligência não verbal. Apenas foram utilizadas para a análise dos dados as correlações que foram significativas até $p<0,05$. Foram consideradas correlações positivas fortes valores entre 0,70 a 1 , moderadas 0,30 a 0,69 e fracas 0 a 0,29 , e correlações negativas fortes, os valores entre $-0,70 \mathrm{a}-1$, moderadas $-0,30 \mathrm{a}-0,69$ e fracas $0 \mathrm{a}-0,29$.

\section{Resultados}

\section{Panorama do Desempenho dos Participantes}

A Tabela 2 apresenta as médias de desempenho em leitura, consciência fonêmica e amplitude visuoatencional, separadamente para cada ano escolar. A análise de variância (ANOVA) revelou um efeito do ano de escolarização sobre todas as variáveis de leitura e de AVA, mas existem divergências nas medidas de consciência fonêmica (ver os valores de $F$ e $M S E$ na Tabela 2). As comparações múltiplas demonstram que o desempenho em leitura das crianças do $1^{\circ}$ ano diferiu significativamente do desempenho das crianças mais velhas, independentemente do tipo de itens de leitura: palavras regulares, $F(2,45)=9,95$; palavras irregulares, $F(2,45)=9,70$; pseudopalavras, $F(2,45)=$ 10,06 , e velocidade de leitura, $F(2,41)=16,69$, todos os $p$ s. $<0,001$. Não se observou diferenças significativas entre as médias do $3^{\circ}$ ano para o $5^{\circ}$ ano em nenhuma das medidas de desempenho em leitura

$\mathrm{Na}$ análise das medidas de consciência fonêmica, a ANOVA revelou que existem diferenças significativas do $1^{\circ}$ ano para os demais anos escolares nas tarefas de deleção fonêmica $F(2,45)=13,78, p<0,001$ e acrônimos $F$ $(2,45)=4,96, p<0,01$. No entanto, não existem diferenças significativas por ano escolar nas médias de segmentação fonêmica $F(2,45)=1,60$ e trocadilhos $F(2,45)=0,64$. As comparações múltiplas indicaram que a média (Conferir Tabela 2) de deleção fonêmica foi significativamente $(p<0,05)$ menor no $1^{\circ}$ ano do que no $3^{\circ}$ ano e no $5^{\circ}$ ano, mas não existem diferenças significativas entre as médias do $3^{\circ}$ ano e do $5^{\circ}$ ano. A média de acrônimos no $1^{\circ}$ ano foi significativamente menor do que a do $3^{\circ}$ ano, mas não existe diferença significativa do $1^{\circ}$ ano para o $5^{\circ}$ ano, nem do $3^{\circ}$ ano para o $5^{\circ}$ ano. Embora a média do $3^{\circ}$ ano seja superior à do $5^{\circ}$ ano essa diferença não é significativa. A tarefa de segmentação fonêmica parece ter sido muito difícil de ser realizada, com médias inferiores a $50 \%$ de acerto. As médias do $1^{\circ}$ ano e do $5^{\circ}$ foram menores do que a média do $3^{\circ}$ ano, no entanto, a ANOVA revelou que não há diferenças significativas entre as médias de segmentação fonêmica em todos os anos estudados. $\mathrm{Na}$ tarefa de trocadilhos observou-se que os alunos do $5^{\circ}$ tiveram melhor desempenho do que os alunos do $3^{\circ}$ ano, mas não existem diferenças significativas entre as médias de trocadilhos.

A ANOVA revelou um progresso significativo das habilidades de AVA com o aumento nos anos de escolarização. Verifica-se diferença significativa $(p<0,001)$ nas medidas de relato global de letras $F(2,45)=20,69$, relato global de conjuntos $F(2,45)=14,19$ e relato parcial $F$ $(2,45)=(2,45)=10,89$. As comparações múltiplas permitiram afirmar que o desempenho das crianças do $1^{\circ}$ ano no relato global de letras foi significativamente $(p<0,05)$ menor do que o desempenho das crianças mais velhas. Foi observada também diferença significativa $(p<0,05)$ entre o desempenho do $3^{\circ}$ ano para o $5^{\circ}$ ano, sugerindo um progresso contínuo no aumento da habilidade de relato global de letras com o progresso na escolarização. O desempenho em relato global de conjuntos do $1^{\circ}$ ano foi menor do que o desempenho do $3^{\circ}$ ano e do $5^{\circ}$ ano. No entanto, estatisticamente só existe diferença significativa $(p<0,05)$ entre as médias do $1^{\circ}$ ano para o $5^{\circ}$ ano e entre o $3^{\circ}$ ano para o $5^{\circ}$ ano. Não foram encontradas diferenças significativas do $1^{\circ}$ ano para o $3^{\circ}$ ano na tarefa de relato global de conjuntos. Ressalta-se que em todos os anos escolares as crianças tiveram mais dificuldades nessa medida, uma vez que devido à exigência de recordar o conjunto completo de 5 letras, essa tarefa também requer mais capacidade de memória. As comparações múltiplas demonstraram que existe diferença significativa $(p<0,05)$ da média de relato parcial do $1^{\circ}$ ano para o $3^{\circ}$ ano e $5^{\circ}$ ano, mas não existe diferença significativa do $3^{\circ}$ ano para o $5^{\circ}$ ano. 
Tabela 2

Médias de Desempenho em Leitura, Consciência Fonêmica, Amplitude Visuoatencional e Tarefas de Controle para Cada Ano Escolar

\begin{tabular}{|c|c|c|c|c|c|c|}
\hline & $1^{\circ}$ Ano & $3^{\circ}$ Ano & $5^{\circ}$ Ano & ANOV & & $\begin{array}{c}\text { Teste } \\
\text { Post Hoc }\end{array}$ \\
\hline & Média $(D P)$ & Média $(D P)$ & Média $(D P)$ & $F(g l)$ & MSE & $p<0,05$ \\
\hline Leitura & - & - & - & - & - & \\
\hline $\begin{array}{l}\text { Palavras regulares } \\
\text { (porcentagem) }\end{array}$ & $61,56(43,95)$ & $94,06(4,46)$ & $98,43(2,21)$ & $9,95(2,45)^{* *}$ & 652,40 & $1^{\circ}<3^{\circ}$ e $5^{\circ}$ \\
\hline $\begin{array}{l}\text { Palavras irregulares } \\
\text { (porcentagem) }\end{array}$ & $52,81(45,68)$ & $84,53(10,01)$ & $92,97(5,57)$ & $9,70(2,45)^{* *}$ & 739,25 & $1^{\circ}<3^{\circ}$ e $5^{\circ}$ \\
\hline $\begin{array}{l}\text { Pseudopalavras } \\
\text { (porcentagem) }\end{array}$ & $48,44(41,98)$ & $81,87(10,31)$ & $85,62(11,42)$ & $10,06(2,45)^{* *}$ & 666,35 & $1^{\circ}<3^{\circ}$ e $5^{\circ}$ \\
\hline $\begin{array}{l}\text { Velocidade de leitura } \\
\text { (segundos por palavras) }\end{array}$ & $4,73(2,46)$ & $2,33(0,49)$ & $1,99(0,31)$ & $16,69(2,41)^{* *}$ & 1,75 & $1^{\circ}<3^{\circ}$ e $5^{\circ}$ \\
\hline Consciência Fonêmica & - & - & - & - & - & \\
\hline $\begin{array}{l}\text { Deleção fonêmica } \\
\text { (porcentagem) }\end{array}$ & $35,31(38,14)$ & $76,25(18,57)$ & $81,87(21,20)$ & $13,78(2,45)^{* *}$ & 749,83 & $1^{\circ}<3^{\circ}$ e $5^{\circ}$ \\
\hline Acrônimos (porcentagem) & $51,88(41,35)$ & $83,75(9,57)$ & $71,87(26,64)$ & $4,96(2,45)^{*}$ & 836,94 & $\begin{array}{c}1^{\circ}<3^{\circ} \text { e } 5^{\circ}, \\
3^{\circ}>5^{\circ}\end{array}$ \\
\hline $\begin{array}{l}\text { Segmentação fonêmica } \\
\text { (porcentagem) }\end{array}$ & $27,08(37,27)$ & $46,66(27,11)$ & $37,08(27,21)$ & $1,60(2,45)$ & 954,94 & $n s$ \\
\hline Trocadilhos (porcentagem) & - & $28,75(28,72)$ & $38,12(36,92)$ & $0,64(1,30)$ & 1093,96 & $n s$ \\
\hline Amplitude Visuoatencional & - & - & - & - & - & \\
\hline $\begin{array}{l}\text { Relato global de letras } \\
\text { (porcentagem) }\end{array}$ & $59,93(15,51)$ & $74,69(8,68)$ & $86,44(9,65)$ & $20,69(2,45)^{* *}$ & 136,36 & $1^{\circ}<3^{\circ}<5^{\circ}$ \\
\hline $\begin{array}{l}\text { Relato global de conjunto } \\
\text { (porcentagem) }\end{array}$ & $12,50(21,60)$ & $25,31(19,95)$ & $55,31(27,72)$ & $14,19(2,45)^{* *}$ & 544,37 & $1^{\circ}$ e $3^{\circ}<5^{\circ}$ \\
\hline $\begin{array}{l}\text { Relato parcial } \\
\text { (porcentagem) }\end{array}$ & $45,12(23,01)$ & $71,50(12,10)$ & $73,62(20,86)$ & $10,89(2,45)^{* *}$ & 370,43 & $1^{\circ}<3^{\circ}$ e $5^{\circ}$ \\
\hline Tarefas de Controle & - & - & - & - & - & \\
\hline $\begin{array}{l}\text { Identificação de letras } \\
\text { (pontuação ponderada) }\end{array}$ & $134,31(21,15)$ & $146,12(5,12)$ & $147,62(3,91)$ & $5,22(2,45)^{*}$ & 163,09 & $1^{\circ}<3^{\circ}$ e $5^{\circ}$ \\
\hline $\begin{array}{l}\text { Memória fonológica } \\
\text { (soma de OD e OI) }\end{array}$ & $9,94(1,88)$ & $11,00(1,93)$ & $11,37(2,24)$ & $2,17(2,45)$ & 4,10 & $n s$ \\
\hline $\begin{array}{l}\text { Inteligência não verbal } \\
\text { (percentil) }\end{array}$ & $85,25(19,28)$ & $81,31(14,81)$ & $81,62(17,51)$ & $0,26(2,45)$ & 299,29 & $n s$ \\
\hline
\end{tabular}

Notas. $1^{\circ}$ ano: $N=16$ (exceto para velocidade de leitura: $n=12$ ), $3^{\circ}$ ano $N=16$ e $5^{\circ}$ ano $N=16 ; n s=$ não é estatisticamente significativo. $* p<0,01 ; * * p<0,001$.

Correlações entre Leitura, Consciência Fonêmica e Amplitude Visuoatencional

$\mathrm{Na}$ Tabela 3, valores acima da diagonal mostram correlações entre as variáveis controlando o efeito da idade. Inteligência não verbal, limiar de identificação de letras e memória fonológica foram controlados juntamente com a idade nas correlações parciais cujos valores estão expostos abaixo da diagonal da Tabela 3 . Em negrito estão todas as correlações significativas a $p<0,05$. 
Observa-se na matriz de correlações parciais, controlando apenas a idade, que as tarefas de consciência fonêmica e de AVA estão correlacionadas com todas as medidas de leitura. Observa-se também que as correlações entre as medidas de consciência fonêmica, especialmente as medidas de deleção fonêmica, são as mais fortemente associadas à leitura de palavras irregulares e pseudopalavras (Conferir valores na Tabela 3 ). As correlações entre as medidas de AVA e leitura são fracas e moderadas sendo que essas correlações são ligeiramente mais fortes entre as medidas de AVA e de leitura de palavras irregulares e pseudopalavras. Dentre as variáveis de controle se observa que a memória fonológica se correlaciona com quase todas as medidas, o que sugere que os dados da primeira correlação parcial podem ter o efeito da memória fonológica.

Quando se controlou o efeito das variáveis de controle, foram observadas correlações entre as medidas de consciência fonêmica e leitura, principalmente entre deleção fonêmica e leitura de palavras irregulares e pseudopalavras. Destaca-se que apenas as pseudopalavras se mantiveram correlacionadas com todas as medidas de consciência fonêmica. Com relação à AVA, foi encontrado um número menor de correlações com as medidas de leitura, mas ainda assim as medidas de relato global de letras e relato parcial se mantiveram associadas à leitura em todos os anos de escolarização.

Foram feitas análises de correlação parcial controlando o efeito da idade e controlando o efeito de todas as variáveis de controle para cada ano escolar. Essas análises permitiram especificar melhor as relações entre leitura, AVA e consciência fonêmica em cada ano escolar. Observou-se que a maior parte das correlações significativas estavam no $1^{\circ}$ ano do ensino fundamental. Foram encontradas apenas algumas correlações entre leitura, consciência fonêmica e AVA no $3^{\circ}$ e no $5^{\circ}$ ano. Como as variáveis de controle, especialmente a memória fonológica, tiveram efeito sobre os cálculos de correlação parcial em todos os anos escolares, optou-se por discutir apenas as correlações já descontando o efeito das variáveis de controle.

$\mathrm{Na}$ análise de correlação parcial descontando o efeito de todas as variáveis de controle (idade, memória fonológica, inteligência não verbal e limiar de identificação de letras), foram observadas no $1^{\circ}$ ano as seguintes correlações entre leitura e consciência fonêmica: (a) positivas e fortes para palavras regulares e acrônimos $(r=0,75, p<0,01)$, palavras irregulares e acrônimos $(r=0,83, p<0,001)$ e pseudopalavras e acrônimos $(r=0,86, p<0,001)$; (b) positivas e moderadas para palavras irregulares e deleção fonêmica $(r$ $=0,69, p<0,05)$ e para pseudopalavras e deleção fonêmica $(r=0,68, p<0,05)$; (c) negativas e fortes para velocidade de leitura e deleção fonêmica $(r=-0,81, p<0,01)$ e para velocidade de leitura e acrônimos $(r=-0,72, p<0,05)$.

Nessa análise de correlação parcial descontando o efeito de todas as variáveis de controle não foram encontradas correlações significativas entre a velocidade de leitura e as medidas de AVA no $1^{\circ}$ ano. Por outro lado, foram encontradas as seguintes correlações entre leitura e AVA: (a) positiva e forte para pseudopalavras e relato parcial $(r=0,71, p<0,01)$; (b) positivas e moderadas para palavras regulares e relato parcial $(r=0,61$, $p<0,05)$, palavras irregulares e relato global de letras $(r$ $=0,59, p<0,05)$, palavras irregulares e relato parcial $(r$ $=0,67, p<0,05)$, pseudopalavras e relato global de letras $(r=0,67, p<0,05)$.

No $3^{\circ}$ ano controlando todas as variáveis, foi encontrada correlação positiva e moderada apenas entre palavras regulares e segmentação fonêmica $(r=0,63, p<0,05)$, pseudopalavras e segmentação fonêmica $(r=0,60, p<0,05)$ e entre palavras irregulares e trocadilhos $(r=0,61, p<0,05)$. Ainda no $3^{\circ}$ ano a medida de AVA relato parcial se correlacionou forte e negativamente com a velocidade de leitura $(r=-0,70, p<0,01)$. No $5^{\circ}$ ano controlando todas as variáveis de controle encontrou-se apenas uma correlação negativa e moderada entre pseudopalavras e relato global de letras $(r=0,57, p<0,05)$.

\section{Discussão}

Os resultados deste estudo sugerem que a AVA se correlaciona com o desempenho em leitura em todos os anos escolares. No entanto, essas associações não são homogêneas entre as medidas de AVA e nem são iguais em todos os anos escolares. Observou-se que a AVA parece ter um papel mais importante no $1^{\circ}$ ano e que essa influência diminui ao longo do processo de escolarização. Bosse e Valdois (2009), em seu estudo com crianças francesas, também encontraram relações mais fortes entre a AVA e a leitura no $1^{\circ}$ ano, e uma diminuição nessa associação com o aumento dos anos de escolarização. Esses resultados parecem indicar que com o aprimoramento da habilidade de leitura as palavras passam a ser lidas de modo global, sendo cada vez menos necessária a decodificação e, portanto, o papel da AVA parece diminuir. Observou-se também que as medidas de relato global de letras e relato parcial se mantiveram correlacionadas principalmente com a leitura de pseudopalavras e palavras irregulares em todos os anos escolares. Esses resultados sugerem que a AVA, por contribuir mais especificamente para a identificação e análise de unidades ortográficas sublexicais relevantes, tem um papel mais importante - desde a aprendizagem inicial até a leitura fluente - na leitura de palavras com irregularidades ortográficas ou palavras novas, como as pseudopalavras. Os dados sugerem, que assim como no francês (Bosse et al., 2013; Bosse \& Valdois, 2009), existe uma relação específica entre a AVA e a aprendizagem de conhecimentos ortográficos. Estudos futuros poderão esclarecer melhor essas relações entre AVA e a leitura de pseudopalavras e palavras irregulares.

Os resultados deste estudo também indicam que a consciência fonêmica se associou com a leitura em todos os anos escolares. No entanto, cada medida de consciência fonêmica parece contribuir de um modo especifico para cada medida de leitura. Verificou-se que a consciência 
Sargiani, R. A., Maluf, M. R. \& Bosse, M.-L. (2015). O Papel da Amplitude Visuoatencional e da Consciência Fonêmica na Aprendizagem da Leitura.

fonêmica parece ter um papel mais importante na leitura no $1^{\circ}$ ano do que no $3^{\circ}$ ano e no $5^{\circ}$ ano. Como no $1^{\circ}$ ano os alunos ainda estão aprendendo a ler, a decodificação é muito importante e utilizada para ler palavras novas ou não familiares, e a consciência fonêmica parece contribuir justamente para a habilidade de decodificação (Ehri, 2013b; Morais et al., 2013; Yopp \& Yopp, 2000).

A consciência fonêmica apresenta relações mais fortes com a leitura do que a AVA. No entanto, tanto a consciência fonêmica quanto a AVA parecem contribuir mais fortemente para a leitura no $1^{\circ}$ ano, porque contribuem para a habilidade de decodificação. Com o progresso na escolarização, muitas das palavras passam a ser lidas por meio das representações ortográficas já previamente armazenadas (Ehri, 2013a, 2013b; Valdois, 2010), minimizando assim a necessidade do uso da decodificação para a leitura, o que pode explicar a diminuição nas correlações entre consciência fonêmica, AVA e leitura com o avanço na escolarização.

Ressalta-se que as correlações entre a leitura e as medidas de segmentação fonêmica e trocadilhos não foram significativas, pois de modo geral essas tarefas de consciência fonêmica foram mais difíceis de serem realizadas. No $5^{\circ}$ ano, por exemplo, foram observados resultados muito baixos, inclusive inferiores ao desempenho dos alunos do $3^{\circ}$ ano. No entanto, não é possível afirmar que as crianças tiveram resultados baixos nessas tarefas por desconhecerem fonemas ou porque "desaprenderam", uma vez que, em todas as outras tarefas eles demonstraram conhecimentos fonêmicos. Esses resultados sugerem, portanto, que com o avanço na escolarização e o domínio do princípio alfabético os alunos são mais guiados pelo significado das palavras e pelo conhecimento do código alfabético do que pelos fonemas em si, o que pode ter interferido no desempenho deles. De modo geral, os alunos do $3^{\circ}$ ano e do $5^{\circ}$ ano se orientavam mais pelo domínio da ortografia do que pelas instruções das tarefas de consciência fonêmica. Na tarefa de segmentação fonêmica, por exemplo, a palavra "carro" era pronunciada " $\mathrm{c}-\mathrm{a}-\mathrm{r}-\mathrm{r}-\mathrm{O}$ " (nomes das letras) ao invés de " $/ \mathrm{k} /-/ \mathrm{a} /-/ \mathrm{R} / \mathrm{-} / \mathrm{O} /$ " (fonemas), embora os alunos tivessem sido instruídos, durante o treino, que deveriam falar os fonemas e que a letra "c" poderia ter som de /s/ ou $/ \mathrm{k} /$ dependendo da palavra (e.g. foca e bacia).

Com relação às implicações pedagógicas dos resultados deste estudo, professores podem se beneficiar desses conhecimentos introduzindo em sua prática atividades que conduzam os alunos a focalizar mais a atenção nos aspectos visuais e sonoros das palavras. Os professores podem fazer isso, por exemplo, por meio de jogos e atividades como "jogo da forca" (adivinhação das palavras por letras), palavras cruzadas, com o uso de dicionários para a correção ortográfica e o ensino de palavras homófonas, homônimas e homógrafas. Estudos anteriores já demonstraram que a instrução sistemática em fonêmica/fonologia auxilia na aprendizagem da linguagem escrita. Com as novas investigações que enfatizam também o papel das habilidades visuoatencionais, hipotetiza-se que o treino em habilidades visuoatencionais pode também contribuir para o ensino mais eficaz da linguagem escrita. Assim, novos estudos longitudinais e de intervenção, além de estudos com amostras maiores, poderão contribuir para responder a essas questões e ampliar os resultados do presente estudo.

\section{Referências}

Adams, M. J. (1999). Beginning to read:Thinking and learning about print. Cambridge, MA: Massachusetts Institute of Technology Press.

Alloway, T. P., Gathercole, S. E., Willis, C., \& Adams, A.M. (2004). A structural analysis of working memory and related cognitive skills in young children. Journal of Experimental Child Psychology, 87(2), 85-106. doi:10.1016/j. jecp.2003.10.002

Angelini, A. L., Alves, I. C. B., Custódio, E. M., Duarte, W. F., \& Duarte, J. L. M. (1999). Matrizes Progressivas Coloridas Escala Especial Revista. São Paulo, SP: Centro Editor de Testes e Pesquisa em Psicologia.

Ans, B., Carbonnel, S., \& Valdois, S. (1998). A connectionist multiple-trace memory model for polysyllabic word reading. Psychology Review, 105(4), 678-723. doi:10.1037/0033-295X.105.4.678-723

Bosse, M.-L., Chaves, N., Largy, P., \& Valdois, S. (2013). Orthographic learning during reading: The role of whole-word visual processing. Journal of Research in Reading. doi:10.1111/j.1467-9817.2012.01551.x

Bosse, M.-L., Tainturier, M. J., \& Valdois, S. (2007). Developmental dyslexia: The visual attention span deficit hypothesis. Cognition, 104(2), 198-230. doi:10.1016/j.cognition.2006.05.009

Bosse, M.-L., \& Valdois, S. (2009). Influence of the visual attention span on child reading performance: A cross-sectional study. Journal of Research in Reading, 32(2), 230-253. doi:10.1111/j.1467-9817.2008.01387.x

Bradley, L., \& Bryant, P. E. (1983). Categorizing sounds and learning to read: A causal connection. Nature, 301(5899), 419-421. doi:10.1038/301419a0

Capovilla, F. C., Capovilla, A. G. S., \& Macedo, E. C. de. (1998). Validação do software CronoFonos para análise de tempo de reação, duração e freqüência de segmentação locucionais na leitura em voz alta de itens isolados. Ciência Cognitiva: Teoria, Pesquisa e Aplicação, 2(3), 253-340.

Castles, A., \& Coltheart, M. (2004). Is there a causal link from phonological awareness to success in learning to read? $\mathrm{Cog}$ nition, 91(1), 77-111. doi:10.1016/S0010-0277(03)00164-1

Corrêa, M. F., \& Cardoso-Martins, C. (2012). O papel da consciência fonológica e da nomeação seriada rápida na alfabetização de adultos. Psicologia: Reflexão e Crítica, 25, 802-808. doi:10.1590/S0102-79722012000400020

Deacon, S. H., \& Kirby, J. R. (2004). Morphological awareness: Just "more phonological"? The roles of morphological and phonological awareness in reading development. Applied Psycholinguistics, 25(2), 223-238. doi:10.1017/ S0142716404001110

Dubois, M., De Micheaux, P. L., Noel, M. P., \& Valdois, S. (2007). Preorthographical constraints on visual word recognition: Evidence from a case study of developmental surface dyslexia. Cognitive Neuropsychology, 24(6), 623-660. doi:10.1080/02643290701617330 
Ehri, L. C. (2013a). Aquisição da habilidade de leitura de palavras e sua influência na pronúncia e na aprendizagem do vocabulário (S. R. N. d. Carvalho, Trad.). In M. R. Maluf \& C. Cardoso-Martins (Eds.), Alfabetização no século XXI: Como se aprende a ler e a escrever (Vol. 1, pp. 49-81). Porto Alegre, RS: Penso.

Ehri, L. C. (2013b). O desenvolvimento da leitura imediata de palavras: Fases e estudos. In M. J. Snowling \& C. Hulme (Eds.), A ciência da leitura (pp. 153-172). Porto Alegre, RS: Penso.

Figueiredo, V. L. M. de. (2002). WISC-III: Escala de Inteligência para Crianças: Manual. São Paulo, SP: Casa do Psicólogo.

Gayan, J., \& Olson, R. K. (2003). Genetic and environmental influences on individual differences in printed word recognition. Journal of Experimental Child Psychology, 84(2), 97-123. doi:10.1016/S0022-0965(02)00181-9

Guimarães, S. R. K. (2005). Aprendizagem da leitura e da escrita: O papel das habilidades metalingüísticas. São Paulo, SP: Vetor.

Harm, M. W., \& Seidenberg, M. S. (1999). Phonology, reading acquisition, and dyslexia: Insights from connectionist models. Psychological Review., 106(3), 491-528. doi:10.1037/0033-295X.106.3.491

Lobier, M., Zoubrinetzky, R., \& Valdois, S. (2012). The visual attention span deficit in dyslexia is visual and not verbal. Cortex, 48(6), 768-773. doi:10.1016/j.cortex.2011.09.003

Maluf, M. R. (2005). Ciência da leitura e alfabetização infantil: Um enfoque metalingüístico. Boletim Academia Paulista de Psicologia, 25(2), 55-62.

Maluf, M. R., \& Sargiani, R. de A. (2013). Lo que la neurociencia tiene que decir sobre el aprendizaje de la lectura. Revista de Psicología de Arequipa, 3(1), 9-23.

Maluf, M. R., Zanella, M. S., \& Pagnez, K. S. M. M. (2006). Habilidades metalingüísticas e linguagem escrita nas pesquisas brasileiras. Boletim de Psicologia, 56(124), 67-92.

Morais, J., Leite, I., \& Kolinsky, R. (2013). Entre a pré-leitura e a leitura hábil: Condições e patamares da aprendizagem. In M. R. Maluf \& C. Cardoso-Martins (Eds.), Alfabetização no século XXI: Como se aprende a ler e escrever (Vol. 1, pp. 17-48). Porto Alegre RS: Penso.

Pinheiro, Â. M. V. (2006). Leitura e escrita: Uma abordagem cognitiva. São Paulo, SP: Pleno.

Plaza, M., \& Cohen, H. (2007). The contribution of phonological awareness and visual attention in early reading and spelling. Dyslexia, 13(1), 67-76. doi:10.1002/dys.330

Salles, J. F. de. (2005). Habilidades e dificuldades de leitura e escrita em crianças de $2^{a}$ série: Abordagem neuropsicológica cognitiva (Tese de doutorado em Psicologia, Universidade Federal do Rio Grande do Sul, Porto Alegre, RS, Brasil).

Santos, M. J. dos, \& Maluf, M. R. (2010). Consciência fonológica e linguagem escrita: Efeitos de um programa de intervenção. Educar em Revista, 57-71. doi:10.1590/S010440602010000300005

Sargiani, R. de A. (2013). Amplitude visuoatencional, consciência fonêmica e desempenho em leitura: Um estudo transversal com alunos do ensino fundamental (Dissertação de mestrado em Psicologia da Educação, Pontifícia Universidade Católica de São Paulo, SP, Brasil). Recuperado em http://www.sapientia.pucsp.br/tde busca/arquivo.php?codArquivo=15451

Share, D. L. (2004). Orthographic learning at a glance: On the time course and developmental onset of self-teaching. Journal of Experimental Child Psychology, 87(4), 267-298. doi:10.1016/j.jecp.2004.01.001
Spinillo, A. G., Mota, M. M. P. E. da, \& Correa, J. (2010). Consciência metalinguística e compreensão de leitura: Diferentes facetas de uma relação complexa. Educar em Revista, 157171. doi:10.1590/S0104-40602010000300011

Valdois, S. (2008). Dyslexies développementales: théorie de l'empan visuo-attentionnel. Approches Neuropsychologiques des Apprentissages de l'Enfant, 96(97), 213-219.

Valdois, S. (2010). Evaluation des difficultés d'apprentissage de la lecture. Revue Française de Linguistique Appliquée, 15(1), 89-103.

Yopp, H. K., \& Yopp, R. H. (2000). Supporting phonemic awareness development in the classroom. The Reading Teacher, 54(2), 130-143.

Ziegler, J. C., \& Goswami, U. (2005). Reading acquisition, developmental dyslexia, and skilled reading across languages: A psycholinguistic grain size theory. Psychological Bulletin, 131(1), 3-29. doi: 10.1037/0033-2909.131.1.3 